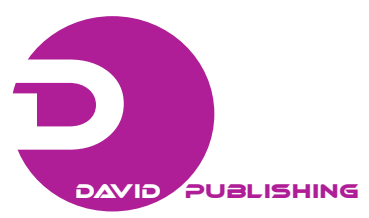

\title{
Refurbishment of Significant Timber Structures in Slovakia
}

\author{
Jaroslav Sandanus and Kristian Sogel \\ Department of Steel and Timber Structures, Slovak University of Technology, Bratislava 81368, Slovakia
}

\begin{abstract}
The paper presents an analysis and a subsequent refurbishment of significant buildings in Slovakia. The analysis focuses on the load-bearing timber roof-structures. There are three sacral objects and one long-span sporting hall presented. The paper tries to introduce the background of difficult refurbishment process. Before the refurbishment, a thorough process of investigation is required. This process includes four basic steps. General information about the load-bearing structure is obtained from the geodetic survey that foregoes the process of diagnostic inspection. The diagnostic survey focuses on the defects of the structure, their degree and possible origin. Modern methods of computer modelling help to understand the structural operation and help to find reserves of carrying capacity. Structural analysis should take into account all detected defects and the joint types, which can influence the transfer of forces. The refurbishment project is usually a brief, but clear summary for fulfilling the needs of Monument Board and building process. All the steps require knowledge from different fields and require professional approach.
\end{abstract}

Key words: Timber, diagnosis, refurbishment, sacral architecture.

\section{Introduction}

The International Charter for conservation and restoration of monuments and historical sites, known as the Venice Charter, was the first document that mentioned the bearing structures in terms of the monument protection. It was accepted at the International Congress of Architects and Technicians of historical monuments in Venice in 1964 [1]. Moreover, it states that a conservation and restoration of monuments is a field that requires cooperation with all the science and technology fields, being able to assist in research and maintenance of architectural heritage. Restoration is an act which should have a character of exceptionality. Its purpose is to preserve and reveal the aesthetic and historical values of the monuments. It is based on respect for the original building materials and authentic documents. Where traditional techniques are not sufficient, there the durability of the monument can be ensured through

Corresponding author: Kristian Sogel, Ph.D., research field: timber load-bearing structures. E-mail: kristian.sogel@stuba.sk. the use of a modern technological process of conservation, if its effectiveness has been demonstrated by scientific research and experience is guaranteed. Whilst maintaining monuments, the preserving method is mostly applied.

The authors are active structural engineers and also members of research organization. Connecting the two fields creates good background for special tasks of structural analysis. The mentioned constructions were the most interesting works from the group of refurbishment.

In the refurbishment, the effort is to protect the substance of historical object, and also to respect all changes connected with the historical development, which demonstrate the natural phenomenon of "aging" of monuments. In practice, this means that the aim of the preserving action is essentially only to stop or at least slow down the natural process of degradation of historical work. In this way, the monument can remain in its authenticity for the future generations. 


\section{The Towers of Premonstratesian Monastery}

The monastery of Premonstratensian's abbey in Jasov (Fig. 1) belongs to the most famous sacral areas in Slovakia. The first church and monastery in Jasov was built in 1228. The monument had been destroyed and rebuilt many times during the 13th and 15th century. The monastery was completely razed in the 18th century and a new late-baroque monastery was built in its place. The monastery consists of two symmetrically positioned two-storied buildings, located on the sides of the central single-nave church with two towers in its facade. Because of its urban, architectural and artistic qualities, it has been a national monument since 1970.

Reconstruction of the monastery has been carried out for several years. After the reparation the roofs and renewal of cladding, the reconstruction of the towers has started. The wooden structure of the tower is $15 \mathrm{~m}$ high. Towers are anchored to the bottom brick building with steel drawbars. The structure has an octagonal floor plan. The tower contains eight main columns placed on the edges of octagon. Columns are supported with a system of pitched supports and are placed on the horizontal cross beams of the base. At the altitude of $9.5 \mathrm{~m}$, there is the bearing cross of tower's helmet. Both crosses are made of oak wood.
The other timber elements were made of red spruce and spruce [2].

The investor's intention was the complete replacement of the cover plates, which were damaged in several places. This caused degradation of the decking and some bearing elements. The aim of the diagnostic survey was to determine the extent of damage in wooden elements by biotic and abiotic cankers. The first step in the reconstruction of historic buildings is a geodetic survey. After the survey, the detailed diagnostic inspection follows, which focuses on the biotic and mechanical damage of the bearing structural elements and connections. Based on detailed survey and diagnostic inspection, the static analyses of the object was carried out and consequently a project of the reconstruction (Fig. 2). During the diagnostic survey, it was found out that the structure of the towers are not reinforced sufficiently. In one of the towers, the spatial reinforcement lacked, which prevents twisting the tower structure. This tower was slightly twisted around its vertical axis in the time of inspection. On the base of the diagnostic inspection and expertise of static load-bearing elements and their connections, the design of reconstruction has been carried out. First it was necessary to strengthen the tower base, because of biotic damage by the supporting walls. Furthermore, it was necessary to completely replace the elements of

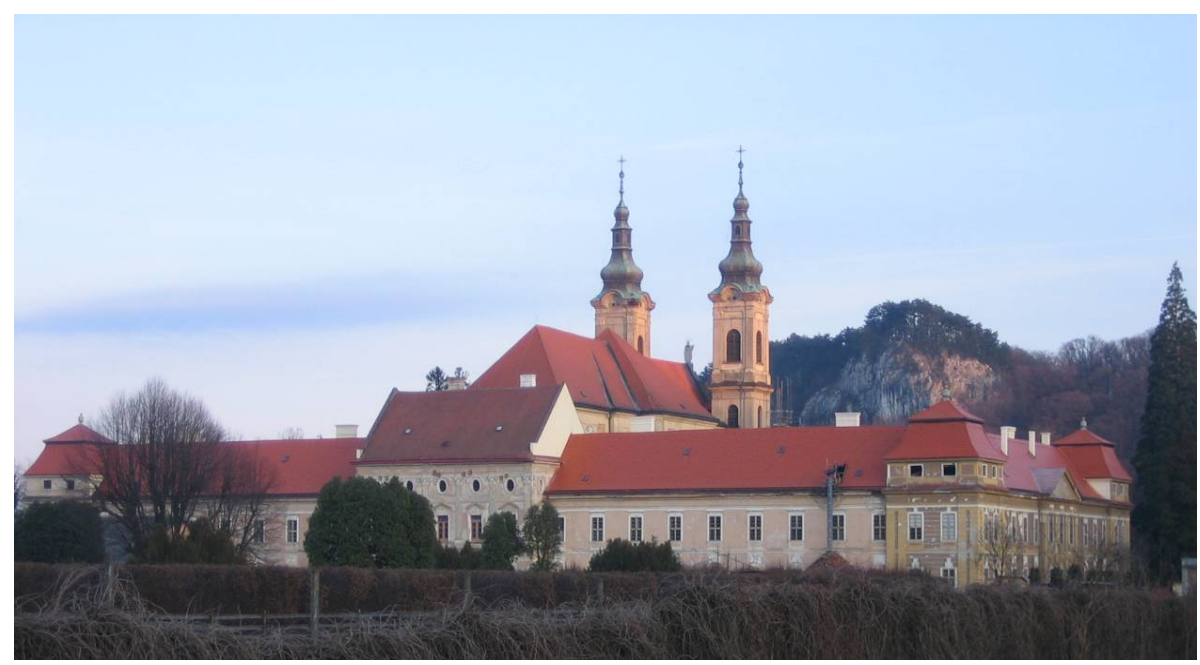

Fig. 1 View of the monastery from the northern side [2]. 


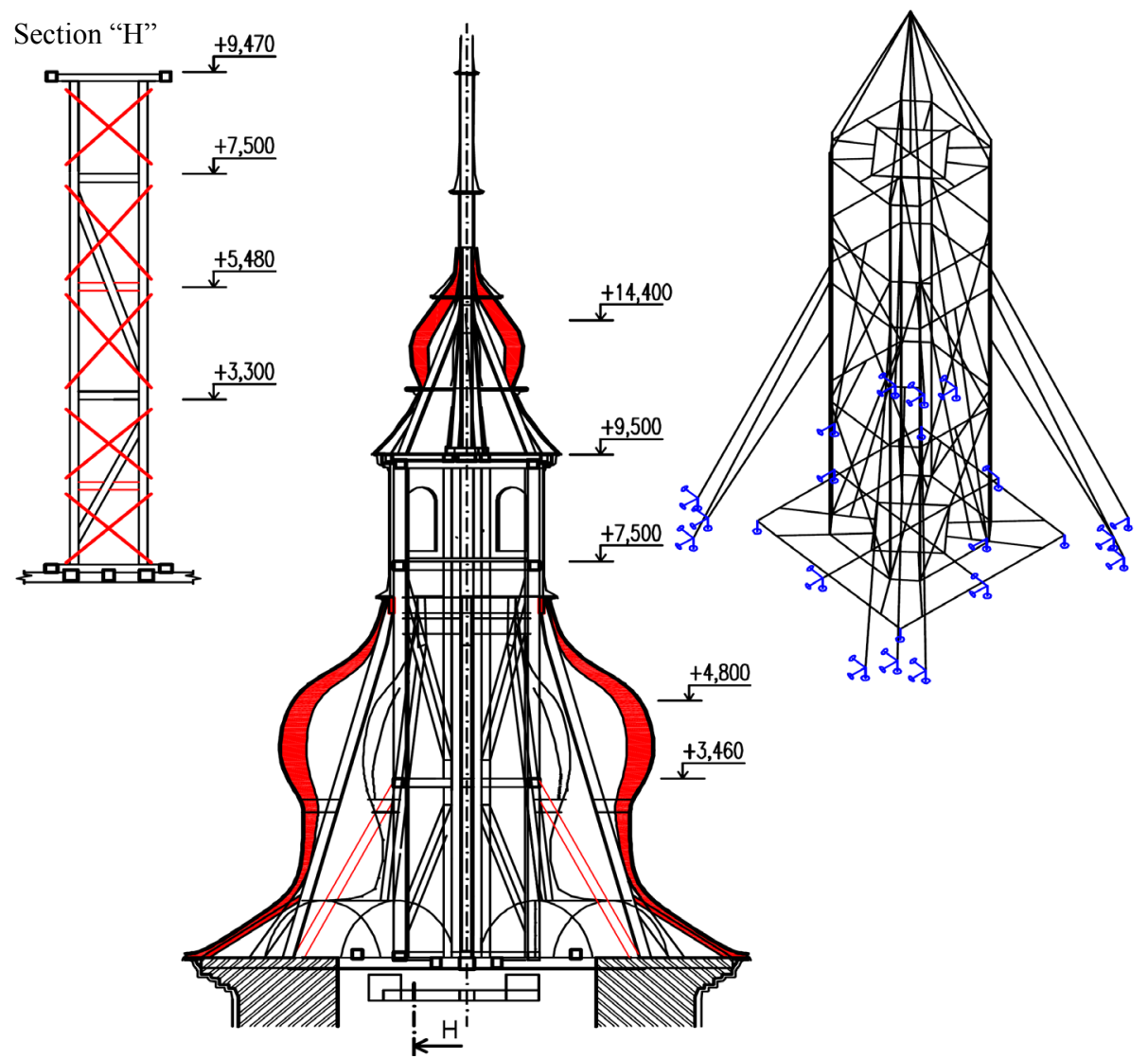

Fig. 2 Cross section of the tower "A", wall bracing proposal, spatial FEM (finite element method) model of the structure.

onion rings and decking. The new additional steel bracing system with a circle cross section was designed, located between the main supporting columns. The main columns were additionally supported by timber elements, providing better load distribution on the base of the tower. For the case of future inspections, the system of ladders and landings were proposed providing safe access to the highest positions of the towers. Besides the safe access, the landings are increasing the spatial rigidity of the structure.

\section{The Piarist's Church in Prievidza}

The church in Prievidza is a significant monument not only in Slovak, but also for the European architecture (Fig. 3). The construction of the single-nave church and the adjacent monastery started in 1666. The church was built according to a model of the church Il Gesu in Rome. The church got its present form in 1753 . The church has a barrel vault and a roof of saddle shape. The distances between columns are approximately $4 \mathrm{~m}$ in longitudinal direction. The covering is made of copper plates supported by laths [3].

The expert's report was carried out by Prof. Ladislav Reinprecht in 2006. This report was concerning the aspect of health of wooden structural parts. Based on this assessment, the authors were invited to work out the proposal for reconstruction. Subsequently the detailed diagnostic inspection was carried out. During the inspection, some serious deficiencies of the structure were indentified. Failures of the covering have been detected in many places, being the cause of degradation of wooden material. The most harmed elements were located near the load-bearing walls, wall beams, principals, etc.. It was found out that some drawbars of the vault were removed. Other drawbars had great deflection therefore were ineffective. This could also cause the cracks that occurred in the main brick vault. The 


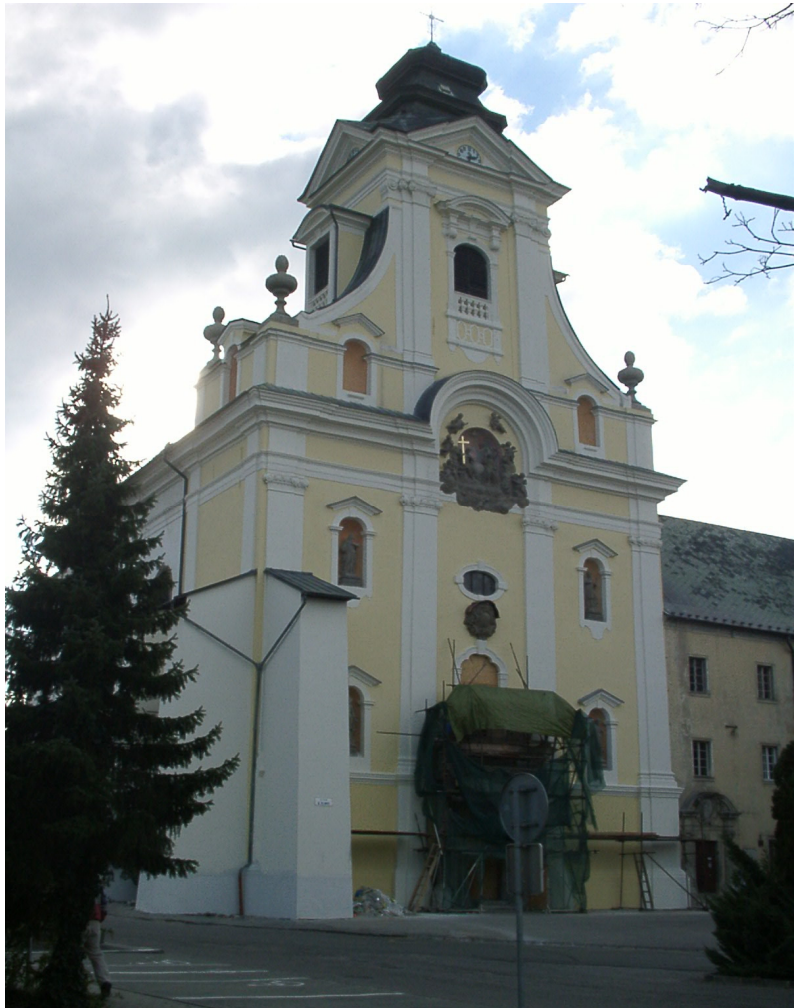

Fig. 3 Piaristic church in Prievidza [3].

circumstances about the drawbar disassembly are unknown. In the attic space and in the interior of the church, geodetic targets are equipped, with the aid of which the movements of individual points are monitoring. In 2007, this monitoring showed that the observed points did not change their position during a period of one year. In order to save that favourable state, it was necessary to propose the new system of steel drawbars and to activate the existing bars by pre-stressing.

The new drawbars were embedded in the positions where they do not load the vault vertically. The proposed system of drawbars has three main parts: horizontal component, oblique component, and column (Fig. 4). Horizontal bar has an adjustable rectification and it goes over the top edge of the vault. The deflection of horizontal drawbar caused by its self-weight is eliminated with the aid of short steel rods anchored to a supplementary beam, which are placed on the principals. The oblique bar, which is embedded in a prepared hole in the masonry, is anchored in the outer side of the church. The bar is anchored to the bearing steel plate that can be hidden by a plaster. The vertical column carries compressive force from the oblique bar into the masonry.

\section{The Chapel in Bratislava}

According to the available historical sources, the chapel dates back to about 1780 and is probably the remaining part of an unbuilt baroque church (Fig. 5).

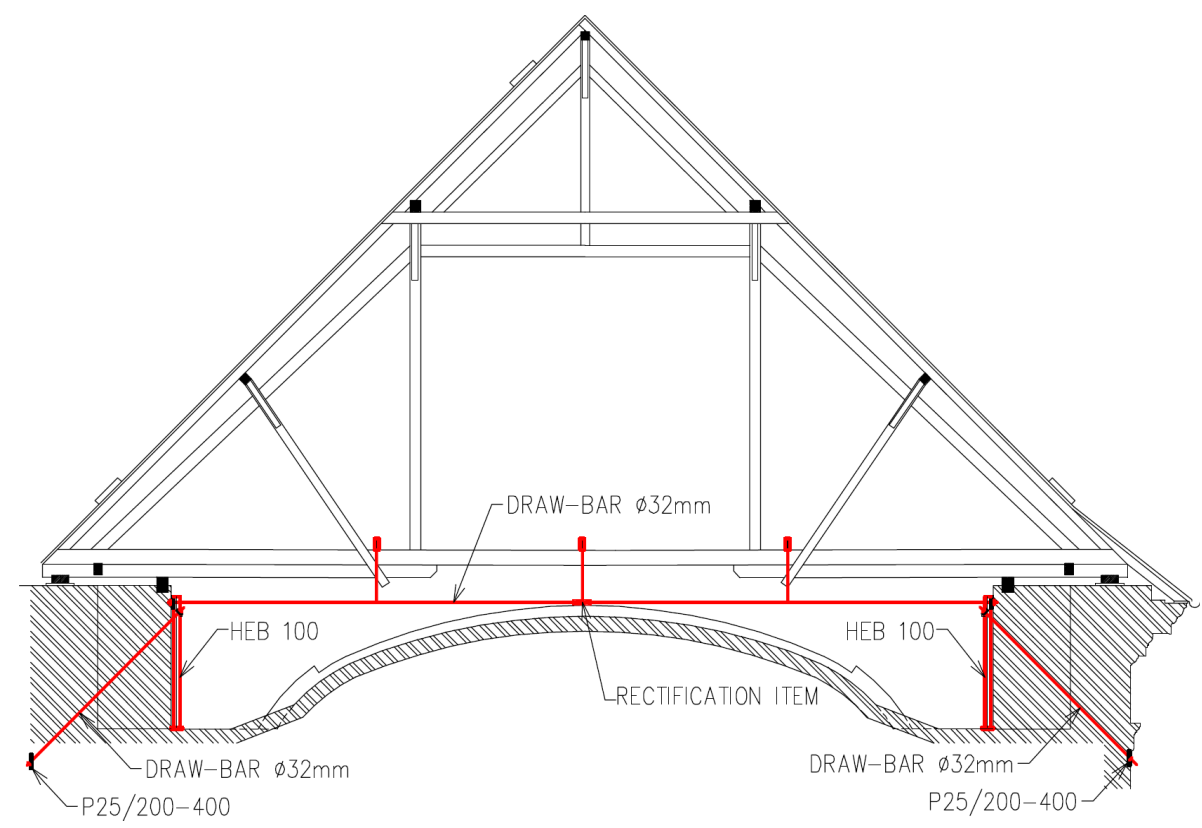

Fig. 4 Proposal of the drawbar system. 
Reconstruction of the baroque chapel began at the "last" moment. Serious condition of the chapel can also be evaluated by an observant passerby. The tower of chapel was inclined towards the altar. The geodetic survey obtained horizontal deformation of the tower of about $0.5 \mathrm{~m}$ at its highest point. Serious defects of principals and other beams causing the inclination of the tower were detected during the diagnostic inspection (Fig. 6). The moisture of wooden components was measured with a portable moisture-meter. In many elements, an absolute moisture content above $35 \%$ was detected, which was not corresponding to the equilibrium moisture content of wood for the climatic conditions in the attic in the time of inspection. This state was measured also in places where the direct leakage of rainwater could not appear. According to the measured values of wood's moisture content, it is likely that the covering of the church does not fulfil its function in terms of tightness and in terms of vapour impermeableness [4].

The last renovation of the wooden structure was inexpert, because the original structure was repaired in an amateur way by adding various additional elements, which had very little static efficiency. Structural elements were not protected against progressive decay. The intervention to the load-bearing structure in such degree was very insensitive and induced further rapid degradation of wooden components. As the supporting points, the vault was used, what can not be acceptable in terms of load bearing system and did not match to the original idea of the load-bearing system.

Based on the diagnostic inspection, emergency condition was announced. Consequently, the project of reconstruction was worked out, with the aim to maintain the original structure. It was necessary to cooperate with the Regional Monuments Board during the design works, seeing that most of the original elements could not be saved. For this reason, a new structure was worked out as a real copy of the original roof structure, using material from the same plants and using the same covering (Fig. 7). In terms of indoor climate of the attic space, it was necessary to create effective ventilation. The air supply was designed near the wall beams and air will be led away through the tower of the chapel.

\section{Sport Hall in Žilina}

The Sport Hall in Žilina was built in the years 1980-1986. It came from the office of architect Kupkovič and structural engineer Bašista. Andrej Bašista was one of few engineers, who used timber as a load-bearing material for long-span structures. Mostly,
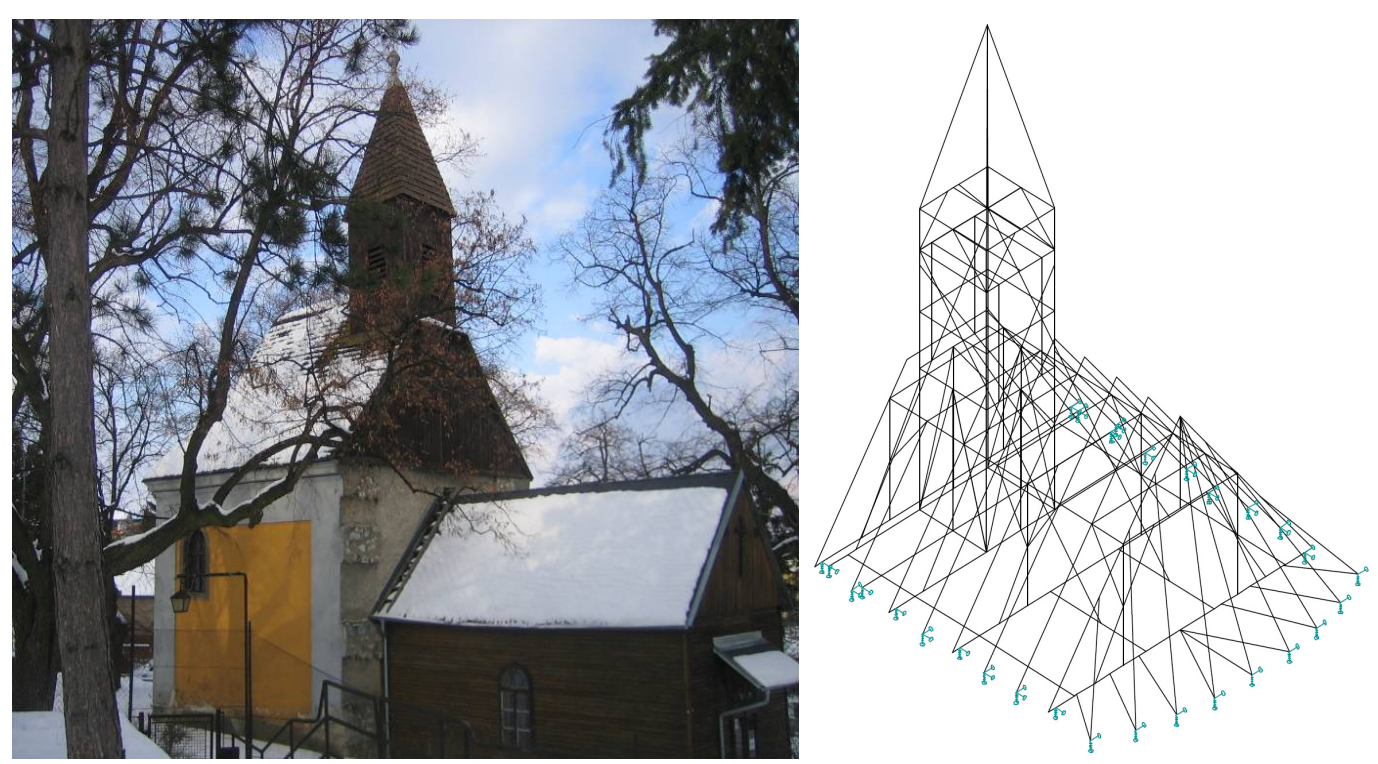

Fig. 5 The chapel of Madonna Mary and its FEM model [4]. 


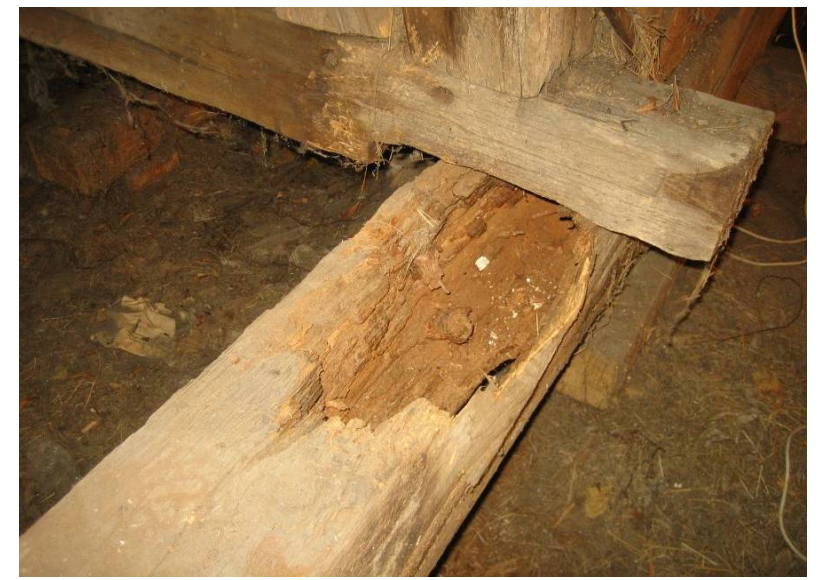

Fig. 6 The highest degree of decay on the principal [4].

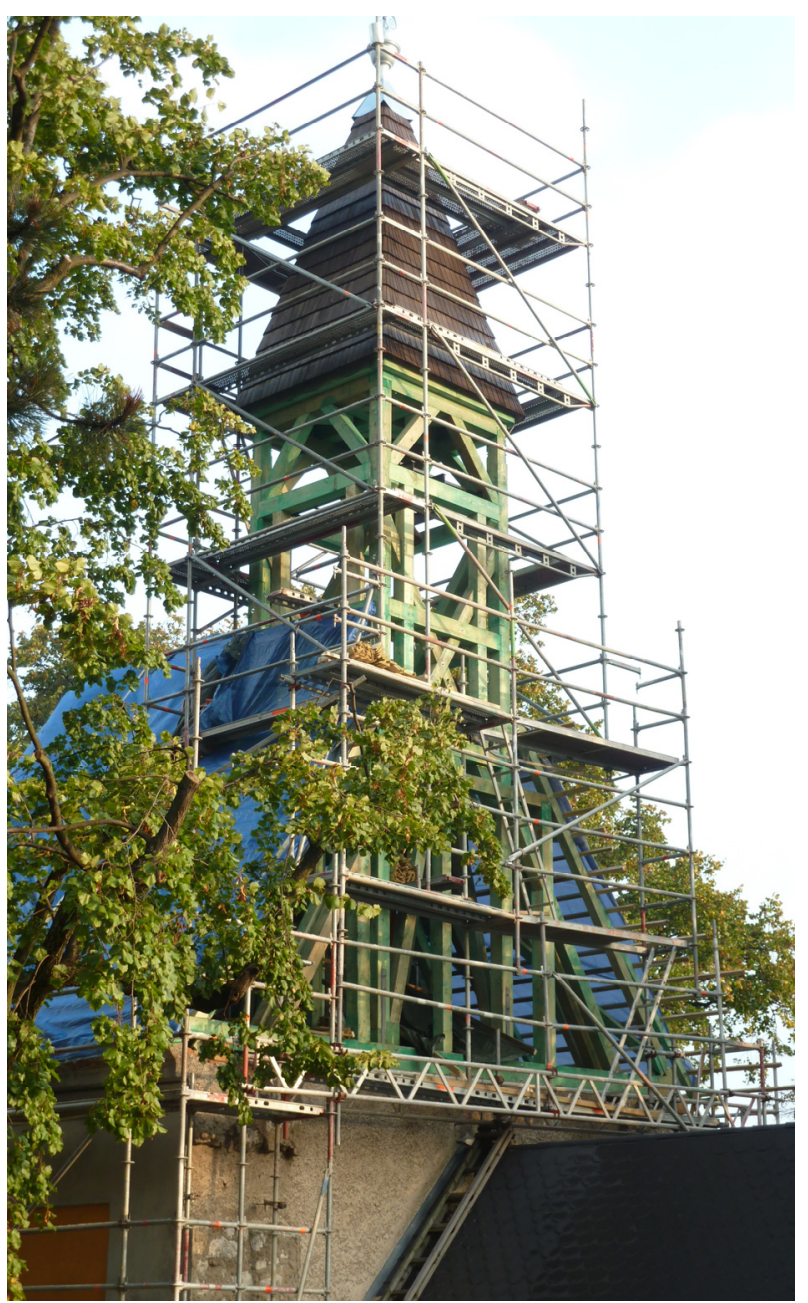

Fig. 7 Copy of the original structure [4].

steel structures were designed in the mentioned period. The span of the spatial vaulted structure is $105 \mathrm{~m}$ (Fig. 8). The main load-bearing structure consists of radially oriented ribs made of glue-laminated timber.
The ribs are variable high from $800 \mathrm{~mm}$ till 1,900 mm by the width $230 \mathrm{~mm}$ (Fig. 9). Six transverse rings are situated between the ribs. These rings are made of glue-laminated timber, too [5].

The staff of the Department of Steel and Timber Structures was invited to the diagnostic inspection of the main structure in 2008. The inspection should be a part of project which assumed a purpose change of the hall. During the inspection, some faults of the main structure were observed. In fact, there are two main faults of the structure. First is the global deformation of the ribs that arise during the construction. The spatial timber structure did not have any reinforcement in the phase of construction. That is why a rotational deformation of the ribs occurred that can be seen especially by the supports. The second kind of failure is a presence of cracks that were probably caused by unsuitable technological conditions by gluing the lamellas (Fig. 10). The glue-laminated elements were produced in a temporary production hall in the building site. Perhaps that is why the moisture content of the wood was higher in the phase of gluing. The maximum depth of the cracks was $80 \mathrm{~mm}$ in one side of the cross section.

Based on the inspection results, the static assessment was worked out concerning the new architectural design. In static calculations, all the faults have been taken in account. The deformed shape of the structure has an influence on the internal forces and the cracks are causing higher shear forces in the cross section.

Some other structural engineers were invited to make an inspection and assessment of the load-bearing structure in the same time. A lot of them considered a dangerous condition of the glue-laminated elements and recommended the removal of the object. Despite all the lacks of the construction, the structure could be repaired and ensure its safe use. It would be a pity to think about the removal of the timber structure, which span and structure is unique in Europe. 


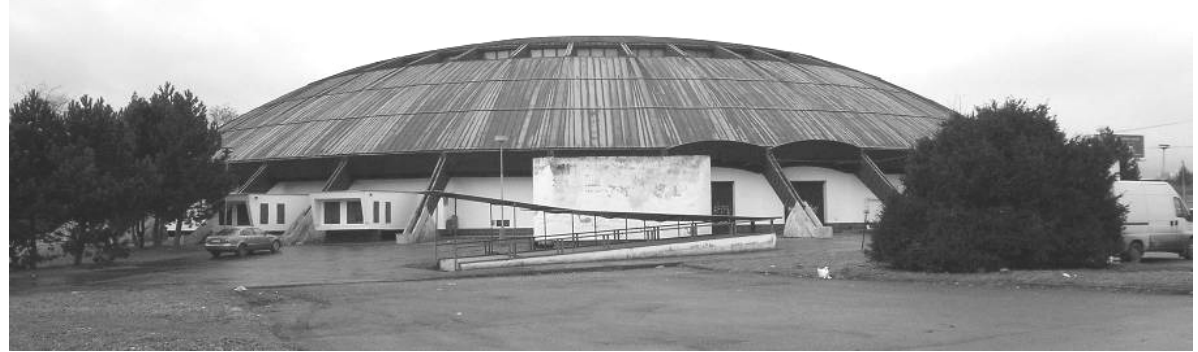

Fig. 8 View at the sport hall [5].

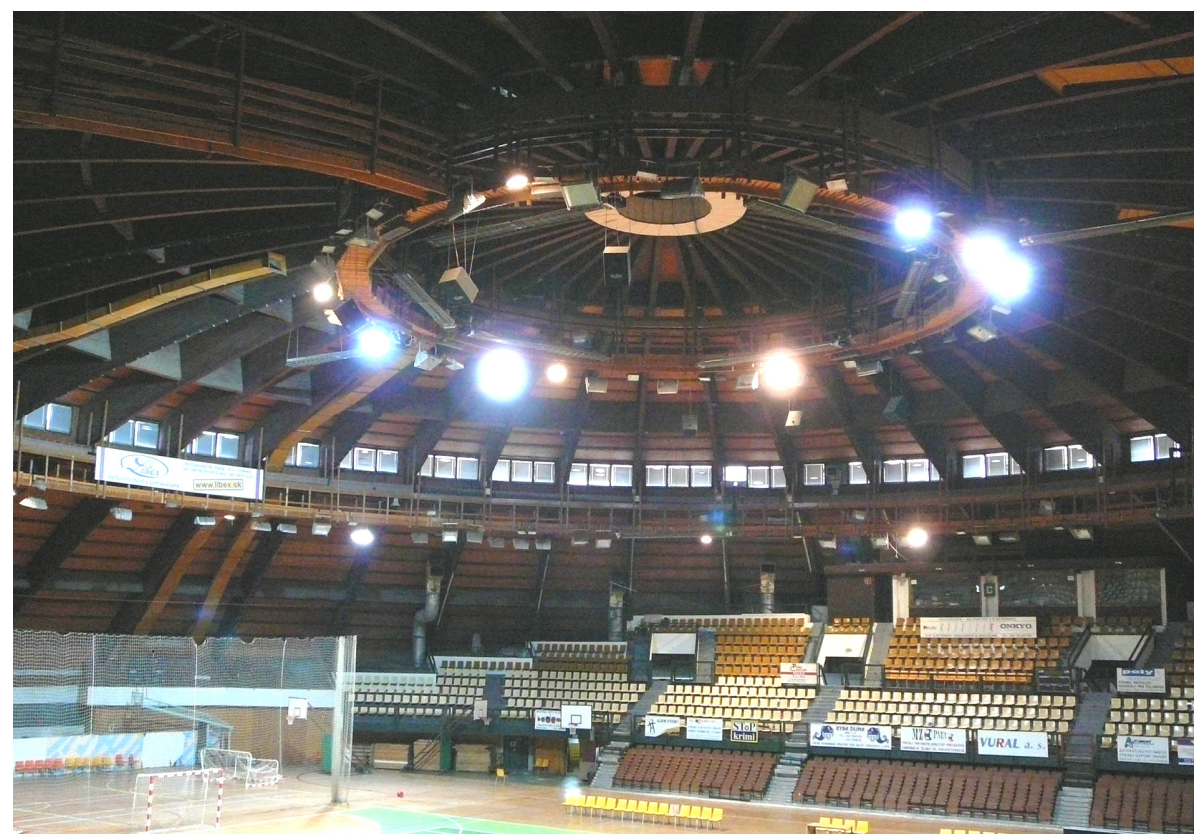

Fig. 9 The interior [5].

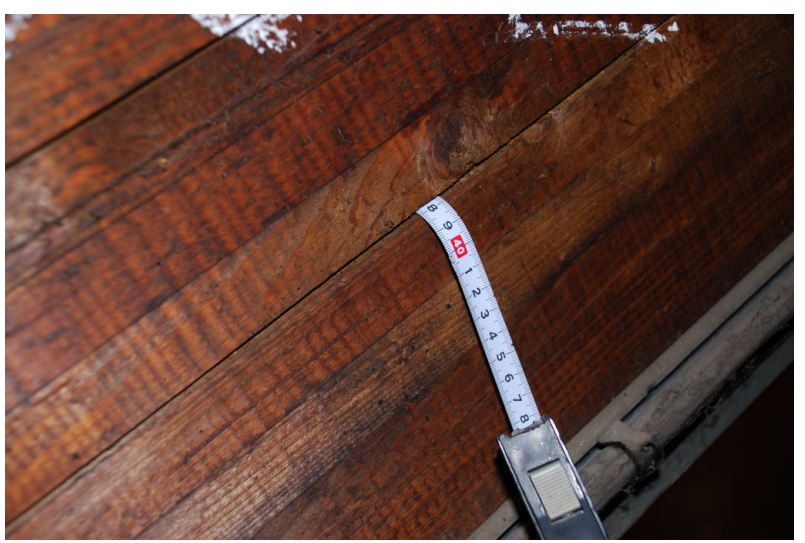

Fig. 10 Cracks on the surface of glue-laminated timber [5].

\section{Conclusions}

A renovation of load-bearing structures of the historic monuments is a very specific field, where the requirements to keep the monument in the most origin state and the demands for the safety and reliability of the structure meet each other. In the process of reconstruction of historical monuments, it is necessary to take into account several factors, which influence the activities of a designer. It is necessary to harmonize the demands of Monument Boards, investors, architects, structural engineers and contractors. A timber structure requires a cooperation of experts with knowledge of the wooden material and experts who are aware of the function of various elements in the structure. Knowing the functions of the elements, many of them could be saved in accordance to the requirements of the monument, because in spite of the defects, the dimensions of the cross sections are usually sufficient for bearing the loads. It is always in favour, if the designer works 
with an experienced contractor during the design and communicates with each other. After the reconstruction, the regular inspections by an authorized person are important to save the monument as much as possible for the next generations.

\section{References}

[1] Venice Charter, The International Charter for the Conservation and Restoration of Monuments and Historical Sites, 1964.

[2] J. Sandanus, K. Sógel, The Survey of Tower's Wooden Structure Biotic Damage of the Monastery in Jasov and the Project of Refurbishment, Slovak University of Technology, Bratislava, 2008.

[3] J. Sandanus, K. Sógel, The Refurbishment Project of Wooden Roof Structure and the Design of the Drawbar System of the Church in Prievidza, Slovak University of Technology, Bratislava, 2008.

[4] J. Sandanus, K. Sógel, Restoration Project, 1st Stage, Roof Structure and Sheet Restoration of Roman Catholic Chapel of Rosary Virgin Mary, Bratislava, Dubravka, 2010.

[5] J. Sandanus, F. Draškovič, K. Sógel, M. Slivanský, T. Živner, Detailed Diagnostic Examination of Wooden Load-Bearing Structure of the Sports Hall in Žilina, Slovak University of Technology, 2008. 